\title{
Ocular Myasthenia Analysis of Diagnostic and Treatment Options
}

\author{
Austin Hake and Henry J. Kaminski \\ Department of Neurology \& Psychiatry, Saint Louis University, St. Louis, MO
}

USA

\section{Introduction}

Myasthenia gravis (MG) is an autoimmune disease of the neuromuscular junction caused by antibodies directed towards the skeletal muscle nicotinic acetylcholine receptor (AChR), the muscle specific kinase (MuSK), and perhaps as yet undefined antigens, which compromise neuromuscular transmission (Figure 1) (Vincent et al. 2001; Conti-Fine et al. 2006). The disorder has a distinct predilection for the ocular muscles - the extraocular muscles (EOM), which move the globe, and the levator palpebrae that elevates the eyelid (Kusner et al. 2006). MG may produce weakness of any skeletal muscle to varying degrees with the potential for a broad range of clinical presentations (Seybold 1999; Kuks and Oosterhuis 2003); however, almost all patients will have ocular manifestations during the disease course, and a large subset will have manifestations restricted to the ocular muscles, so-called ocular myasthenia (OM) (Kusner et al. 2006). Diagnostic tests for OM include clinical evaluations, serum autoantibodies, and electrophysiological evaluation, all of which differ in their diagnostic predictive value depending on whether a patient has generalized MG or OM (Roh et al. 2011). Treatment for OM includes well-studied modalities; however, none that are supported by rigorous, controlled trials. This analysis will discuss the ocular manifestations, diagnostic testing, and treament of OM, with a focus on the current evidence to support clinical decision-making (Luchanok and Kaminski 2008).

\section{Epidemiology}

MG has a prevalence of $20-400$ per million based on large population studies, and OM comprises approximately $20 \%$ of all cases (Somnier et al. 1991; Phillips et al. 1992; Christensen et al. 1993; Phillips and Torner 1996; MacDonald et al. 2000; Casetta et al. 2010). The classic statement of the disease being of old men and young woman is true with an age distribution being bimodal with incidence peaks in the 20's for women and 40's for men (Phillips and Torner 1996; Grob 1999; Mantegazza et al. 2003; Vincent et al. 2003; Matsuda et al. 2005). OM is more likely to present at a later age and is more often seen in men (Gilbert and Savino 2007). In Asian populations, OM is more common and has a distinct predilection for a juvenile onset, quite different from that observed in European and American populations (Chiu et al. 1987; Hawkins et al. 1989; Wong et al. 1992). One study from South Africa found that $\mathrm{OM}$ in the black population was more likely to be treatment resistant than in the white (Heckmann et al. 2007). 


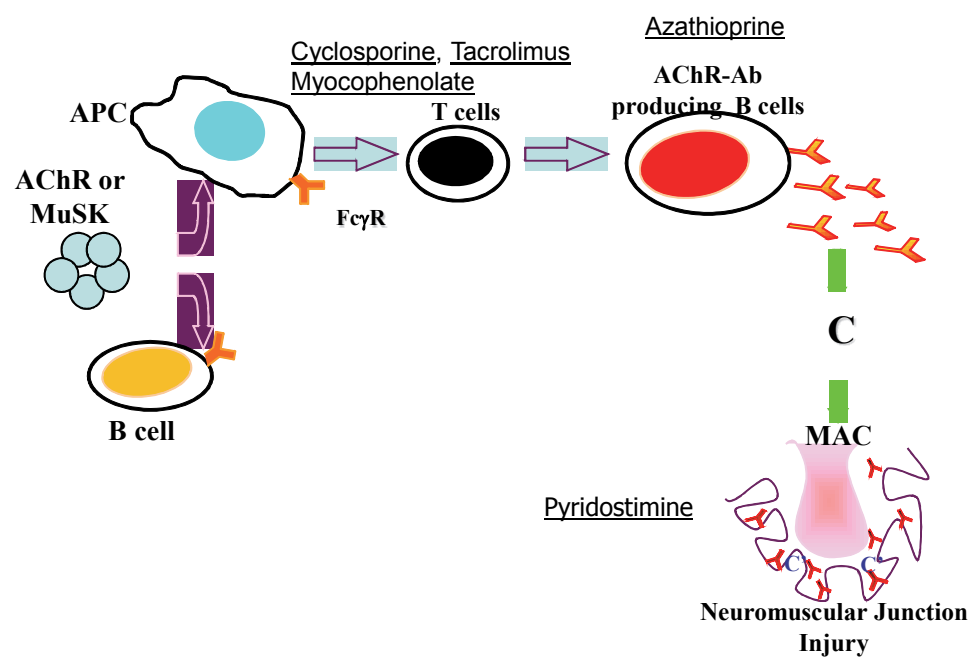

Fig. 1. Summary of Myasthenia Gravis Pathogenesis. Antibodies directed at neuromuscular junction proteins are produced by B cells under T cell regulation. Antibodies compromise the AChR density at the neuromuscular junction and thereby impair neuromuscular transmission producing weakness. Treatments used for ocular myasthenia are indicated. APC-antigen presenting cell.

\section{Ocular manifestations of myasthenia gravis}

Over seventy-five percent of MG patients initially present with ptosis or diplopia and almost all MG patients experience ocular manifestations sometime during the course of the disease (Beekman et al. 1997; Barton and Fouladvand 2000; Daroff and Benatar 2009). About half of patients who present with isolated ocular manifestations develop generalized weakness within six months and up to eighty percent will generalize within 2 years (Bever et al. 1983; Oosterhuis 1989; Kupersmith et al. 2003). It is likely that symptoms will remain restricted to the ocular muscles once a patient has had restricted ocular manifestations for over two years (Evoli et al. 1988; Oosterhuis 1989; Grob 1999; Verschuuren et al. 2010). The natural history of the disease impacts therapeutic decision-making.

The hallmark of MG manifestations is their variable nature, which may range in severity over a day, over weeks to months, and include periods of complete resolution. The variations in severity assist in diagnostic recognition of MG but may complicate clinical recognition, if a patient is examined at a time of relative good strength. Ptosis may be unilateral or bilateral, and usually differs in severity between lids. OM is the only diagnostic consideration in a patient with a history of alternating or recurrent painless ptosis (Daroff and Benatar 2009). Some patients do not immediately appreciate lid droop and complain primarily of blurred vision secondary to the lid's obstruction of the pupil. Due Hering's law of equal innervation, central compensation for unilateral ptosis may lead to hyper-retraction of a less affected lid leading to ocular irritation from exposure. When the ptotic lid is manually elevated, the retracted lid droops, a sign commonly considered specific for MG. The presence of Cogan's sign also strongly supports the diagnosis of MG. Cogan's sign is elicited by instructing the patient to look down and then rapidly return the eyes to primary 
gaze. During the refixation, the eyelid overshoots and appears retracted momentarily and then becomes ptotic again (Cogan 1965).

Other causes of ptosis may rarely be confused with OM. Senile ptosis and levator dehiscence are readily differentiated by absence of significant fluctuation. Chronic progressive external ophthalmoplegia produces symmetric ptosis and ophthalmoparesis, but with slow saccades which should distinguish it from OM (Barton et al. 1995; Leigh and Zee 1999; Hirano and DiMauro 2001). Brainstem disorders of the third nerve nuclear complex will usually have associated central nervous system pathology. Horner's syndrome is identified by miosis and elevation of the lower lid, while the ptosis in complete third nerve palsy is associated with pupillary dilatation. Clinically evident pupillary abnormalities never occur in $\mathrm{MG}$, although subclinical alterations in pupillary constriction are reported (Tsiptsios et al. 2008).

Ophthalmoparesis is the second most common manifestation of OM. Most MG patients complain of frank double vision; however, complaints may include dizziness, gait instability, or visual blurring without significant complaints of diplopia. Symptoms may improve with closure of one eye. Nearly $90 \%$ of patients who present with diplopia have associated ptosis, and the combination should immediately lead to the consideration of MG as a diagnosis (Barton and Fouladvand 2000; Elrod and Weinberg 2004; Fouladvand et al. 2005; Daroff and Benatar 2009). The eye movement abnormalities of MG mimic any peripheral or central nervous system ocular motility abnormality, and the degree of impairment varies from paralysis to subtle weakness with isolated nystagmus. Dissociated gaze-evoked nystagmus contralateral to a paretic eye may be observed in OM, which represents adaptive increases in innervational pulse. On dynamic testing, saccadic velocity may be preserved or increased in a limited range of movement (highly suggestive of MG) or intrasaccadic fatigue may be identified when a fast eye movement suddenly slows and becomes disconjugate in mid-flight (Khanna et al. 2007). Graves ophthalmopathy can mimic OM by presence of a restrictive deficit but ptosis is absent and if the patient is thyrotoxic, lid retraction may be present. Ptosis in a patient with Graves disease suggests the coexistence MG.

Orbicularis oculi weakness in combination with ptosis or ophthalmoparesis is a strong indicator of MG (Barton and Fouladvand 2000; Fouladvand et al. 2005). OM may mimic any pupil-sparing ocular motility disorder including fourth, sixth, and partial third nerve palsies, and central gaze disorders, such as internuclear ophthalmoplegia, the one and a half syndrome, and chronic progressive external ophthalmoplegia (Leigh and Zee 1999; Fouladvand et al. 2005; Daroff and Benatar 2009). Other neuromuscular junction disorders may mimic $\mathrm{OM}$ such as Lambert-Eaton myasthenic syndrome, botulism, or organophosphate poisoning, but purely ocular presentations of these disorders are rare. Appropriate history, physical examination, and ancillary testing should distinguish these conditions from MG.

\section{Diagnostic testing}

The diagnosis of OM may be made based on clinical grounds when no other conditions are consistent with a patient's examination and history. However, at times the clinical manifestations are difficult to detect by routine examination or may be absent at time of an examination leading to the need for additional evaluation. In addition, therapy for MG is not benign, and most clinicians and patients desire definitive confirmation of the diagnosis. However, the clinician must appreciate the limitations of tests used for diagnosis. 


\subsection{Edrophonium test}

The edrophonium test involves intravenous infusion of edrophonium chloride, which inhibits the action of acetylcholinesterase (AChE). Procedures for edrophonium administration are not standardized, but in general, an initial $1 \mathrm{mg}$ dose is given to assure patient tolerance followed by slow infusion over a few minutes until improvement in strength of a muscle is observed or a maximum of $10 \mathrm{mg}$ is administered, although $7 \mathrm{mg}$ is usually the maximum required to achieve a positive response (Kupersmith et al. 2003). Because of the objective nature of the response, unequivocal improvement in strength of a ocular muscle is the best endpoint to judge a test as positive (Daroff 1986).

Improvement of ptosis in response to edrophonium may be as high as $95 \%$ and the specificity has been reported at $97 \%$; however EOM weakness does not respond as well to an edrophonium challenge (Nicholson GA 1983; Evoli et al. 1988; Kupersmith et al. 2003; Pascuzzi 2003). However, these high response rates have been determined in the controlled environments of academic institutions and not in standard clinical practices. The specificity of the edrophonium is likely to be high as long as the evaluation is performed by experienced clinicians. The potential for false positives exists, in the busy office practice, especially when the examiner rarely performs such evaluations. Other neuromuscular transmission disorders, such as Lambert-Eaton syndrome and botulism, can also cause a positive response to edrophonium (Oh SJ 1990), and false positive tests are reported with Guillain-Barre syndrome, compressive cranial neuropathies, and brain stem pathology (Pascuzzi 2003; Daroff and Benatar 2009).

There has been concern raised regarding the safety of edrophonium testing, which has led to some institutions requiring cardiac monitoring during the procedure. However, serious complications of bradycardia and syncope are rare (Ing et al. 2000), and it is the authors' opinion that cardiac monitoring is not necessary for most patients. Cardiac dysrhythmias and bronchial asthma are relative contraindications for edrophonium administration. Beyond muscarinic effects of tearing, salivation, sweating, abdominal cramps, and nausea, the test has limited morbidity (Pascuzzi 2003; Daroff and Benatar 2009).

\subsection{Other clinical evaluations}

The ice pack, rest, and sleep tests are non-pharmacological evaluations, which have been developed in order to avoid the need for edrophonium infusion and have close to no morbidity. However, the limitation of all these evaluations is that sensitivity and specificity assessments have been performed (Benatar 2006). All studies have small sample sizes. Interobserver reliability is also not known.

The ice pack test is performed by placement of an ice pack across the eyes for two to five minutes followed by the examiner's assessment for improvement of ptosis or ocular motility deficit (Golnik et al. 1999; Ellis et al. 2000). Some patients may have difficulty tolerating the ice pack. The rest test requests the patient close their eyelids for up to 5 minutes, and then improvement in ptosis is assessed. For the sleep test, the patient lies with eyes closed in a quiet, dark room for 30 minutes and then ptosis and ophthalmoparesis are assessed for improvement. For the ice test, sensitivity of 80-97 percent and specificity of 97-100 percent are reported (Golnik 1997; Golnik et al. 1999; Benatar 2006). In a study of edrophoniumpositive patients all had positive sleep tests as well (Odell et al. 1991). A small, randomized trial compared the ice test to the rest test and found that the median improvement of ptosis with the rest test was $2 \mathrm{~mm}$ and with the ice test $4.5 \mathrm{~mm}$, but no improvement found among 
patients without MG (Kubis et al. 2000). One value of these tests is that they may be performed in patients in whom edrophonium infusion is contraindicated.

\subsection{Serum autoantibody evaluation}

Serum AChR antibody examinations are performed concurrently, or instead of the clinical tests described (Howard et al. 1987). The sensitivity of AChR antibodies testing for OM ranges between 39 and 71 percent. The specificity achieved is 95-100 percent (Benatar 2006). The detection of AChR antibodies may increase the risk of progression to generalized MG, but studies are inconsistent (Seybold 1999; Kupersmith et al. 2003) AChR antibodies have been detected without evidence of MG among patients with autoimmune liver disease, systemic lupus erythematosus, rheumatoid arthritis, Lambert Eaton syndrome, inflammatory neuropathies, amyotrophic lateral sclerosis, thyroid ophthalmopathy, thymoma patients, in patients taking D-penicillamine, and first degree relatives of patients with MG (Lennon 1997). Therefore, their detection is not absolutely specific for the diagnosis.

The binding AChR antibody is the most sensitive test and the studies described above dealt with the binding assay. The modulating $\mathrm{AChR}$ antibody may increase the diagnostic yield slightly for generalized MG patients but has not been assessed for OM. The modulating AChR antibody suffers from higher rates of false positives. The third AChR antibody evaluation is the blocking antibody, but it may only slightly increase sensitivity of the binding assay. Therefore, the authors generally only order the binding AChR antibody examination.

About a three percent of patients with generalized MG have antibodies against MuSK, a neuromuscular junction protein that provides the clustering signal for AChR (Hoch et al. 2001; Liyanage et al. 2002; Evoli et al. 2003; Vincent et al. 2003; Zhou et al. 2004). Rare cases of pure OM in association with MuSK antibodies are described (Caress et al. 2005; Bennett et al. 2006; Chan and Orrison 2007); however, large case series of MuSK antibody positive patients have not identified OM patients, but patients may present with ocular manifestions (Evoli et al. 2003; Zhou et al. 2004). MuSK examinations are about 16 times the cost of the binding $\mathrm{AChR}$ antibody test and therefore, should not be routinely requested unless clinically indicated.

Patients with clinical symptoms of MG with electrophysiological evidence of neuromuscular junction impairment, but no evidence of serum autoantibodies are deemed to have seronegative MG (Argov 2010; Roh et al. 2011). Up to half of OM patients do not have detectable antibodies to the AChR. A small percentage $(15 \%)$ of initially seronegative patients may become seropositive for $\mathrm{AChR}$ antibodies later in the disease course (Chan et al. 2007). With specialized testing two-thirds of patients with generalized MG without traditional antibodies for AChR or MuSK are positive for low-affinity IgG autoantibodies to AChR (Leite et al. 2008). Therefore, even in OM patients pathogenic antibodies may be directed against the AChR but be undetected by standard testing.

\subsection{Electrodiagnosis}

A significant proportion of $\mathrm{OM}$ patients will have negative AChR antibody evaluations and have non-definitive clinical assessments. Electrodiagnostic testing needs then to be performed to objectively confirm a diagnosis of OM. Repetitive nerve stimulation measures the action potential amplitude produced by repetitive low frequency stimulation. A decrement of $10 \%$ or more is considered positive for MG (Oh SJ 1992). The 
sensitivity of repetitive nerve stimulation for OM is poor (11-54 percent), but specificity is high (89-98 percent) (Roh et al. 2011). Evaluation of the orbicularis oculi (especially the lower orbicularis oculi), orbicularis oris, or nasalis will increase the percentage of patients identified, but such evaluations are much more difficult to tolerate for patients than extremity evaluations (Mercelis and Merckaert 2011). Although identification of decremental responses in non-ocular muscles indicates subclinical disease in other muscles, the finding does not indicate the presence or predict progression to generalized MG.

Single fiber electromyography (SFEMG) involves repetitive measures of the time between action potentials of two fibers in a muscle during a slight contraction. Abnormalities occur because of a fiber's slowed transmission of an action potential because of a compromised endplate potential that does not reach threshold. A fiber may not be activated which produces a neuromuscular block. If the mean jitter - time between activation of all fiber pairs (or endplates) - exceeds the upper limit of normal for that muscle, or if more than $10 \%$ of pairs have jitter that exceeds the upper limit of jitter during voluntary activation, then the study is considered abnormal. SFEMG is 62 to 99 percent sensitive for detection of MG, and its specificity is reported to be from 66 to 98 percent (Ukachoke et al. 1994; de Entrambasaguas et al. 2007; Mercelis and Merckaert 2011); however, it implementation is limited due to the requirements of specially-trained, experienced examiners. Although it is labor-intensive, SFEMG should be considered in patients with a strong clinical suspicion for $\mathrm{OM}$ in which repetitive nerve stimulation is negative, due to its higher sensitivity (Srivastava et al. 2007). The SFEMG is also useful in ruling out myasthenic weakness. If the SFEMG is normal in a clinically weak muscle, then the weakness is not due to a neuromuscular transmission disorder (Sanders and Stalberg 1996; Katirji and Kaminski 2002; Meriggioli and Sanders 2004; Sanders 2004).

\subsection{Other evaluations}

When the clinician thinks the OM diagnosis is likely additional testing is necessary. Thyroid dysfunction is a common co-morbidity and therefore, it is appropriate to screen all OM patients for hypo- or hyperthyroidism. Identification of concurrent thyroid dysfunction may improve MG related weakness. If clinically indicated the co-existence of other autoimmune disorders should be evaluated, in particular pernicious anemia, Chest imaging should be performed to exclude thymoma although thymoma is rare in OM patients. In anticipation of immunosuppressive treatments, screening for tuberculosis is appropriate.

\section{Treatment}

The treatment goal for patients with $\mathrm{OM}$ is to produce normal vision with a minimum of adverse effects. Unfortunately, treatment of OM has not been subject to rigorous evaluation and longitudinal studies of the risks of chronic treatment do not exist. Also, the individual tolerance of patients needs to be considered in making treatment recommendations. Some patients with OM respond well to non-pharmacologic therapies that are often overlooked by neurologists. If non- pharmacologic therapies cannot provide adequate relief, acetylcholesterase are typically administered, but the majority of patients do not respond well, and immunosuppressive treatments are required (Table). 


\begin{tabular}{|c|c|c|}
\hline Drug & Cost in USA & Mechanism of action \\
\hline $\begin{array}{l}\text { Pyridostigmine } 60 \\
\text { mg tablets }\end{array}$ & $\$ 17.99$ (30 tabs) & $\begin{array}{l}\text { Inhibits acetylcholinesterase at neuromuscular } \\
\text { junction but also at muscarinic synapses }\end{array}$ \\
\hline $\begin{array}{l}\text { Pyridostigmine } \\
180 \mathrm{mg} \text { controlled } \\
\text { release (time } \\
\text { span) }\end{array}$ & $\$ 137.99(30)$ & \\
\hline $\begin{array}{l}\text { Prednisone } \\
20 \mathrm{mg} \text { tablet }\end{array}$ & $\$ 11.99(30)$ & $\begin{array}{l}\text { Anti-inflammatory effects related to: a) } \\
\text { redistribution of lymphocytes and reduction of } \\
\text { production and differentiation, b) alterations of } \\
\text { function of TNF, IL-1 and IL-2, c) inhibition of } \\
\text { antigen processing and presentation by } \\
\text { macrophage. }\end{array}$ \\
\hline $\begin{array}{l}\text { Immuran® } 50 \mathrm{mg} \\
\text { tablet } \\
\text { Azathioprine } 50 \\
\text { mg tablet }\end{array}$ & $\begin{array}{l}\$ 159.99(30) \\
\$ 27.99(30)\end{array}$ & Inhibits T- and B-cell proliferation \\
\hline $\begin{array}{l}\text { CellCept }{ }^{\circledR} 500 \mathrm{mg} \\
\text { tablet } \\
\text { Mycophenolate } \\
\text { mofetil } 500 \mathrm{mg}\end{array}$ & $\$ 129.99(100)$ & $\begin{array}{l}\text { Inhibits T- and B-cell proliferation through } \\
\text { inhibition of guanosine nucleotide synthesis. Also } \\
\text { produces: a) apoptosis of activated T- } \\
\text { lymphocytes, b) decrease in cell adhesion } \\
\text { molecules thus reducing lymphocyte recruitment, } \\
\text { c) reduction of inducible NOS activity. }\end{array}$ \\
\hline $\begin{array}{l}\text { Prograf® } 1 \mathrm{mg} \\
\text { capsule } \\
\text { Tacrolimus } 1 \mathrm{mg} \\
\text { capsule }\end{array}$ & $\begin{array}{l}\$ 409.94(100) \\
\$ 345.97(100)\end{array}$ & $\begin{array}{l}\text { Calcineurin mediated pathway inhibition of T-cell } \\
\text { and IL-2 production. Modulates the activity of T- } \\
\text { cells, increases their apoptosis and may enhance T } \\
\text { regulatory cells. }\end{array}$ \\
\hline
\end{tabular}

* From Epocrates ${ }^{\circledR}$ online Searched April 2011.

Table 1. Ocular Myasthenia Treatment Options

\subsection{Non-pharmaceutical treatment options}

Ptosis may be improved by eyelid tape or crutches; however, patients often are intolerant of these approaches finding them uncomfortable. Also, scleral irritation may occur by exposure and lead to drying or abrasion. Visual occlusive devices, such as eye patches or opaque contact lenses, eliminate diplopia but reduce the visual field. Custom corrective lenses with prisms may correct diplopia temporarily, but because patients with OM have fluctuation of their visual axes, they require frequent correction of their prism. Prism therapy may be considered in patients with stable strabismus for six months to a year. Eye muscle surgery may be beneficial in rare patients when a fixed strabismus occurs and non-variable ptosis (Ohtsuki et al. 1996; Bentley et al. 2001). Botulinum toxin may also be considered to correct ocular alignment by chemodenervation of the involved extraocular muscles, but it must be used cautiously given the potential for systemic neuromuscular transmission blockade. Although there are challenges associated with the treatments, non-pharmacological options may be favored by some patients and be the only options for patients with disease resistant to pharmacological treatments. 
Thymectomy is not generally indicated of OM, but case series do support its use (Schumm et al. 1985; Roberts et al. 2001). Of course, OM patients with a thymoma should undergo tumor removal and co-incident removal of the remainder of the thymus.

\subsection{Acetylcholesterase inhibition}

AChE inhibitors are the first line of medical treatment for $\mathrm{OM}$, and pyridostigmine is the most commonly used drug in the class. While AChE inhibitors are effective for ptosis, diplopia is of often resistant to treatment (Sommer et al. 1993; Sommer et al. 1997; Mehndiratta et al. 2011). In some patients, unilateral ptosis "unmasks" ocular misalignment producing the symptom of diplopia which may be more troublesome for the patient (Daroff and Benatar 2009). Patients presenting with both ptosis and diplopia tend to have an inferior response to pyridostigmine (Chirapapaisan N 2007), and many OM patients move on to corticosteroid treatment(Kupersmith and Ying 2005).

Pyridostigmine 30-60 mg three to four times per day are typical starting doses and may be increased to 90 to $120 \mathrm{mg}$ every 3-4 hours per day, if symptoms respond and adverse effects are kept to a minimum. Complications are primarily related to muscarinic effects, in particular abdominal cramps, nausea, vomiting and diarrhea, which occur in at least a third of patients (Beekman et al. 1997). Atropine or glycopyrrolate may be used to limit muscarinic activity. AChE inhibitor treatment should be used with caution in patients with bradycardia and prostatic hypertrophy. Patients with MG treated with AChR inhibitors, who have reactive airway disease, may have worsening of respiratory function secondary increased respiratory secretions leading to a false conclusion that respiratory insufficiency is caused by myasthenic weakness. An open label prospective trial demonstrated improved quality of life with the sustained-release form of pyridostigmine, which requires less frequent administration (Sieb and Kohler 2010). However, in the author's experience, more reliable improvements in strength occur with the standard preparation. Cholinergic weakness is often discussed but probably does not occur in this era that patients move to immunotherapy and do not rely on extremely high doses of AChE inhibitors. However, if a clinician is concerned that cholinergic weakness is a cause of worse OM symptoms, the AChE inhibitor may be reduced.

\subsection{Corticosteroid treatment}

Most patients will not receive significant benefit from the non-pharmacological and AChE inhibitor treatments and will choose to proceed to immunosuppressive treatment (Kupersmith and Ying 2005). Prednisone is the most frequently used immunosuppressive treatment for $\mathrm{OM}$, and unless corticosteroids are contraindicated due to comorbities, it is the first-line immunosuppressive for OM. Although this is based on retrospective analysis(Benatar and Kaminski 2007, Bhanushali et al. 2008).

Dosing regimens vary but typically, $10-20 \mathrm{mg}$ once a day is started and increased by $5-10 \mathrm{mg}$ every 3 days until visual symptoms are improved significantly, which usually occurs in the first few weeks of therapy (Kupersmith et al. 2003; Mee et al. 2003; Papapetropoulos et al. 2003). $60-80 \mathrm{mg}$ per day is a maximum dose. At times mild double vision that does not impair function may persist and need to be tolerated. After symptom resolution is maintained for a month, a slow taper is instituted at a rate of 5-10 mg per day every 2 weeks until a dose of $20 \mathrm{mg}$ every day is achieved and the dose reductions slowed further. Rapid tapers often lead to recurrence of symptoms, but even with gradual dose reductions a large 
percentage of patients will have symptom recurrence. Patients will need an increase in dose when symptoms recur. Most patients require maintenance doses for years, which should be the lowest possible to prevent recurrence of visual complaints. More than three-quarters of patients experience significant improvement (Evoli et al. 1988; Sommer et al. 1997; Tackenberg et al. 2001; Kupersmith and Ying 2005). To reduce corticosteroid complications every other day dosing of prednisone may be used. Patients should be instructed to take a single morning dose, which mimics the diurnal peak of endogenous corticosteroid. Patients need to be educated about steroid side effects, which include weight gain, glucose tolerance, hypertension, osteoporosis, insomnia, anxiety, depression, and the numerous other complications of prednisone. The neurologist or ophthalmologist should work with the patient's primary care physician to monitor for complications.

Based on retrospective analysis, corticosteroids may delay or prevent the progression of OM to generalized MG (Agius 2000; Kaminski and Daroff 2000; Kupersmith 2004). However, there has not been a randomized, controlled trial to assess whether steroids have a disease modifying effect (Gilbert et al. 2007; Gilbert and Savino 2007). Future studies should consider visual outcome and quality of life to determine whether the benefits of corticosteriods outweigh the complications of chronic corticosteroid use.

\subsection{Immunotherapy}

Some patients will not respond to corticosteroids, have contraindications to their use, or have intolerable adverse effects necessitating use of other immunotherapies (Tackenberg et al. 2001). Assessment of efficacy for immunosuppressives specific to treatment for $\mathrm{OM}$ is extremely limited and is entirely based on retrospective investigation. Support for their use also derives from administration for the generalized disease, but these studies are also not robust. Azathioprine was demonstrated to reduce corticosteroid requirements in a randomized, placebo-controlled trial of generalized MG patients (Palace et al. 1998), and retrospective analyses support its efficacy in OM patients (Mertens et al. 1981; Matell 1987; Hohlfeld et al. 1988; Mantegazza et al. 1988). The clinician and the patient then need to consider immunosuppressant therapy, and here the evidence base relies on data from the generalized disease and expert opinion. For generalized MG, cyclosporine, tacrolimus, and mycophenolate mofetil have steroid sparing effects demonstrated in double-blind, placebocontrolled or retrospective studies (Sanders and Evoli 2010).

\section{Conclusion}

The analysis provides a focused review of clinical manifestations, diagnosis, and treatment of $\mathrm{OM}$ and highlights the significant limitations of the literature. Diagnosis of $\mathrm{OM}$ is generally straightforward, when the clinician thinks of the disorder. Confirmation of clinical diagnosis is challenging for OM. Serum AChR antibodies are found in only half of patients, and while the MuSK antibody is detected in about three percent of the generalized MG population, it is found only rarely among patients with isolated OM. Therefore the majority of patients lack detectable autoantibodies and confirmation of a neuromuscular transmission disorder relies on specialized, electrophysiological testing. Although expert opinion suggests that treatment is highly effective, significant knowledge gaps exist as to severity of treatment complications and over-all quality of life of patients with OM. Only through prospective trials or multi-center, rigorously constructed outcome databases will improvements in treatment be achieved. 


\section{References}

Agius, M. A. (2000). Treatment of ocular myasthenia with corticosteroids: yes. Arch Neurol 57(5): pp. 750-751.

Argov, Z. (2010). Current approach to seronegative myasthenia. Journal of Neurology 258(1): pp. 14-18.

Barton, J. J. and Fouladvand, M. (2000). Ocular aspects of myasthenia gravis. Semin Neurol 20(1): pp. 7-20.

Barton, J. J., Jama, A. and Sharpe, J. A. (1995). Saccadic duration and intrasaccadic fatigue in myasthenic and nonmyasthenic ocular palsies. Neurology 45(11): pp. 2065-2072.

Beekman, R., Kuks, J. B. and Oosterhuis, H. J. (1997). Myasthenia gravis: diagnosis and follow-up of 100 consecutive patients. J Neurol 244(2): pp. 112-118.

Benatar, M. (2006). A systematic review of diagnostic studies in myasthenia gravis. Neuromuscul Disord 16(7): pp. 459-467.

Benatar, M. and Kaminski, H. J. (2007). Evidence report: the medical treatment of ocular myasthenia (an evidence-based review): report of the Quality Standards Subcommittee of the American Academy of Neurology. Neurology 68(24): pp. 2144-2149.

Bennett, D. L., Mills, K. R., Riordan-Eva, P., Barnes, P. R. and Rose, M. R. (2006). Anti-MuSK antibodies in a case of ocular myasthenia gravis. J Neurol Neurosurg Psychiatry 77(4): pp. 564-565.

Bentley, C. R., Dawson, E. and Lee, J. P. (2001). Active management in patients with ocular manifestations of myasthenia gravis. Eye 15(Pt 1): pp. 18-22.

Bever, C. T., Aquino, A. V., Penn, A. S., Lovelace, R. E. and Rowland, L. P. (1983). Prognosis of ocular myasthenia. Ann Neurol 14: pp. 516-519.

Bhanushali, M. J., Wuu, J. and Benatar, M. (2008). Treatment of ocular symptoms in myasthenia gravis. Neurology 71(17): pp. 1335-1341.

Caress, J. B., Hunt, C. H. and Batish, S. D. (2005). Anti-MuSK myasthenia gravis presenting with purely ocular findings. Arch Neurol 62(6): pp. 1002-1003.

Casetta, I., Groppo, E., Gennaro, R., Cesnik, E., Piccolo, L., Volpato, S. and Granieri, E. (2010). Myasthenia gravis: a changing pattern of incidence. Journal of Neurology 257(12): pp. 2015-2019.

Chan, J. W. and Orrison, W. W. (2007). Ocular myasthenia: a rare presentation with MuSK antibody and bilateral extraocular muscle atrophy. Br J Ophthalmol 91(6): pp. 842-843.

Chan, K. H., Lachance, D. H., Harper, C. M. and Lennon, V. A. (2007). Frequency of seronegativity in adult-acquired generalized myasthenia gravis. Muscle $\mathcal{E}$ Nerve 36(5): pp. 651-658.

Chirapapaisan N, T. S., Chuenkongkaew W (2007). Factors associated with insensitivity to pyridostigmine therapy in Thai patients with ocular myasthenia gravis. Asian Pac J Allergy Immunol 25(1): pp. 13-16.

Chiu, H.-C., Vincent, A., Nemsom-Davis, J., Hsieh, K.-H. and Hung, T.-p. (1987). Myasthenia gravis: population differences in disease expression and acetylcholine receptor antibody titers between Chinese and Caucasians. Neurology 37: pp. 1854-1857.

Christensen, P., Jensen, T., Tsiropoulos, I., Sorensen, T., Kjaer, M., Hojer-Pedersen, E., Rasmussen, M., Lehfeldt, E. and de Fine Olivarius, B. (1993). Incidence and prevalence of myasthenia gravis in western Denmark 1975 to 1989. Neurology 43: pp. 1779-1783. 
Cogan, D. (1965). Myasthenia gravis: a review of the disease and a description of lid twitch as a characteristic sign. Arch Ophthalmol(74): pp. 217-221.

Conti-Fine, B. M., Milani, M. and Kaminski, H. J. (2006). Myasthenia gravis: past, present, and future. J Clin Invest 116(11): pp. 2843-2854.

Daroff, R. and Benatar, M. (2009). Ocular Myasthenia. Myasthenia Gravis and Related Disorders. H. J. Kaminski. Totowa, NJ, Humana Press: 95-104.

Daroff, R. B. (1986). The office tensilon test for ocular myasthenia gravis. Arch Neurol 43: pp. 843-844.

de Entrambasaguas, M., Lopez-Bernabe, R. and Lopez-Alemany, M. (2007). [Ocular myasthenia gravis: diagnostic aspects and evolution]. Rev Neurol 44(7): pp. 397-403.

Ellis, F. D., Hoyt, C. S., Ellis, F. J., Jeffery, A. R. and Sondhi, N. (2000). Extraocular muscle responses to orbital cooling (ice test) for ocular myasthenia gravis diagnosis. J Aapos 4(5): pp. 271-281.

Elrod, R. D. and Weinberg, D. A. (2004). Ocular myasthenia gravis. Ophthalmol Clin North Am 17(3): pp. 275-309; v.

Evoli, A., Tonali, P., Bartoccioni, E. and LoMonaco, M. (1988). Ocular myasthenia: Diagnostic and therapeutic problems. Acta Neurol Scand 77: pp. 31-35.

Evoli, A., Tonali, P. A., Padua, L., Monaco, M. L., Scuderi, F., Batocchi, A. P., Marino, M. and Bartoccioni, E. (2003). Clinical correlates with anti-MuSK antibodies in generalized seronegative myasthenia gravis. Brain 126(Pt 10): pp. 2304-2311.

Fouladvand, M., Ledoux, D. and Barton, J. S. (2005). Ocular Myasthenia Gravis. Comprehensive Opthalmology Update 6: pp. 25-36.

Gilbert, M. E., De Sousa, E. A. and Savino, P. J. (2007). Ocular Myasthenia Gravis treatment: the case against prednisone therapy and thymectomy. Arch Neurol 64(12): pp. 1790-1792.

Gilbert, M. E. and Savino, P. J. (2007). Ocular myasthenia gravis. Int Ophthalmol Clin 47(4): pp. 93-103, ix.

Golnik, K. (1997). An ice test for the diagnosis of myasthenia gravis. Ophthalmology 106(7): pp. 1282-1286.

Golnik, K. C., Pena, R., Lee, A. G. and Eggenberger, E. R. (1999). An ice test for the diagnosis of myasthenia gravis. Ophthalmology 106(7): pp. 1282-1286.

Grob, D. (1999). Natural History of Myasthenia Gravis. Myasthenia Gravis and Myasthenic Disorders. A. G. Engel. New York, Oxford University Press: 131-154.

Hawkins, B. R., Yu, Y. L., Wong, V., Woo, E., Ip, M. S. and Dawkins, R. L. (1989). Possible evidence of a variant of myasthenia gravis based on HLA and acetylcholine receptor antibody in Chinese patients. Quart J Med 70: pp. 235-241.

Heckmann, J. M., Owen, E. P. and Little, F. (2007). Myasthenia gravis in South Africans: Racial differences in clinical manifestations. Neuromuscul Disord.

Hirano, M. and DiMauro, S. (2001). ANT1, Twinkle, POLG, and TP: New genes open our eyes to ophthalmoplegia. Neurology 57(12): pp. 2163-2165.

Hoch, W., McConville, J., Helms, S., Newsom-Davis, J., Melms, A. and Vincent, A. (2001). Auto-antibodies to the receptor tyrosine kinase MuSK in patients with myasthenia gravis without acetylcholine receptor antibodies. Nat Med 7(3): pp. 365-368.

Hohlfeld, R., Michels, M., Heininger, K., Besinger, U. and Toyka, K. V. (1988). Azathioprine toxicity during long-term immunosuppression of generalized myasthenia gravis. Neurology 38: pp. 258-261. 
Howard, F. J., Lennon, V., Finley, J., Matsumoto, J. and Elveback, L. (1987). Clinical correlations of antibodies that bind, block, or modulate human acetylcholine receptors in myasthenia gravis. Ann NY Acad Sci 505: pp. 526-538.

Ing, E. B., Ing, S. Y., Ing, T. and Ramocki, J. A. (2000). The complication rate of edrophonium testing for suspected myasthenia gravis. Can J Ophthalmol 35(3): pp. 141-144; discussion 145.

Kaminski, H. J. and Daroff, R. B. (2000). Controversies in Neurology. Treatment of ocular myasthenia: steroids only when compelled. Arch Neurol 57: pp. 752-753.

Katirji, B. and Kaminski, H. J. (2002). An electrodiagnostic approach to the patient with neuromuscular junction disorder. Neur Clin 20: pp. 557-586.

Khanna, S., Liao, K., Kaminski, H. J., Tomsak, R. L., Joshi, A. and Leigh, R. J. (2007). Ocular myasthenia revisited: Insights from pseudo-internuclear ophthalmoplegia. Journal of Neurology 254(11): pp. 1569-1574.

Kubis, K. C., Danesh-Meyer, H. V., Savino, P. J. and Sergott, R. C. (2000). The ice test versus the rest test in myasthenia gravis. Ophthalmology 107(11): pp. 1995-1998.

Kuks, J. and Oosterhuis, H. J. G. H. (2003). Clinical Presentation and Epidemiology of Myasthenia Gravis. Myasthenia Gravis and Related Disorders. H. J. Kaminski. Totowa, NJ, Humana Press: 93-114.

Kupersmith, M. J. (2004). Does early treatment of ocular myasthenia gravis with prednisone reduce progression to generalized disease? J Neurol Sci 217(2): pp. 123-124.

Kupersmith, M. J., Latkany, R. and Homel, P. (2003). Development of generalized disease at 2 years in patients with ocular myasthenia gravis. Arch Neurol 60(2): pp. 243-248.

Kupersmith, M. J. and Ying, G. (2005). Ocular motor dysfunction and ptosis in ocular myasthenia gravis: effects of treatment. Br J Ophthalmol 89(10): pp. 1330-1334.

Kusner, L. L., Puwanant, A. and Kaminski, H. J. (2006). Ocular myasthenia: diagnosis, treatment, and pathogenesis. Neurologist 12(5): pp. 231-239.

Leigh, R. J. and Zee, D. S. (1999). The Neurology of Eye Movements. Philadelphia, F.A. Davis.

Leite, M. I., Jacob, S., Viegas, S., Cossins, J., Clover, L., Morgan, B. P., Beeson, D., Willcox, N. and Vincent, A. (2008). IgG1 antibodies to acetylcholine receptors in 'seronegative' myasthenia gravis. Brain 131(7): pp. 1940-1952.

Lennon, V. (1997). Serologic profile of myasthenia gravis and distinction from LambertEaton myasthenic syndrome. Neurology 48 (Suppl 5): pp. S23-27.

Liyanage, Y., Hoch, W., Beeson, D. and Vincent, A. (2002). The agrin/muscle-specific kinase pathway: new targets for autoimmune and genetic disorders at the neuromuscular junction. Muscle Nerve 25(1): pp. 4-16.

Luchanok, U. and Kaminski, H. J. (2008). Ocular myasthenia: diagnostic and treatment recommendations and the evidence base. Curr Opin Neurol 21(1): pp. 8-15.

MacDonald, B. K., Cockerell, O. C., Sander, J. W. and Shorvon, S. D. (2000). The incidence and lifetime prevalence of neurological disorders in a prospective communitybased study in the UK. Brain 123(Pt 4): pp. 665-676.

Mantegazza, R., Antozzi, C., Peluchetti, D., Sghirlanzoni, A. and Cornelio, F. (1988). Azathioprine as a single drug or in combination with steroids in the treatment of myasthenia gravis. J Neurol 235: pp. 449-453.

Mantegazza, R., Baggi, F., Antozzi, C., Confalonieri, P., Morandi, L., Bernasconi, P., Andreetta, F., Simoncini, O., Campanella, A., Beghi, E. and Cornelio, F. (2003). Myasthenia gravis (MG): epidemiological data and prognostic factors. Ann $N Y$ Acad Sci 998: pp. 413-423. 
Matell, G. (1987). Immunosuppressive drugs: azathioprine in the treatment of myasthenia gravis. Ann N Y Acad Sci 505: pp. 589-594.

Matsuda, M., Dohi-Iijima, N., Nakamura, A., Sekijima, Y., Morita, H., Matsuzawa, S., Sato, S., Yahikozawa, H., Tabata, K., Yanagawa, S. and Ikeda, S. (2005). Increase in incidence of elderly-onset patients with myasthenia gravis in Nagano Prefecture, Japan. Intern Med 44(6): pp. 572-577.

Mee, J., Paine, M., Byrne, E., King, J., Reardon, K. and O'Day, J. (2003). Immunotherapy of ocular myasthenia gravis reduces conversion to generalized myasthenia gravis. $J$ Neuroophthalmol 23(4): pp. 251-255.

Mehndiratta, M. M., Pandey, S. and Kuntzer, T. (2011). Acetylcholinesterase inhibitor treatment for myasthenia gravis. Cochrane Database Syst Rev 2: pp. CD006986.

Mercelis, R. and Merckaert, V. (2011). Diagnostic utility of stimulated single-fiber electromyography of the orbicularis oculi muscle in patients with suspected ocular myasthenia. Muscle E Nerve 43(2): pp. 168-170.

Meriggioli, M. N. and Sanders, D. B. (2004). Myasthenia gravis: diagnosis. Semin Neurol 24(1): pp. 31-39.

Mertens, H. G., Hertel, G., Reuther, P. and Ricker, K. (1981). Effect of immunosuppressive drugs (azathioprine). Ann N Y Acad Sci 377: pp. 691-699.

Nicholson GA, M. J., Griffiths LR (1983). Comparison of diagnostic tests in myasthenia gravis. Clin Exp Neurol(19): pp. 45-49.

Odell, J. G., Winterkorn, J. M. S. and Behrens, M. M. (1991). The sleep test for myasthenia gravis. Safe alternative to Tensilon. J Clin Neuro Opthalmol 11: pp. 288-292.

Oh SJ, C. H. (1990). Edrophonium responsiveness not necessarily diagnostic of myasthenia gravis. Muscle Nerve(13): pp. 187-191.

Oh SJ, K. D., Kuruoglu R, et al (1992). Diagnostic sensitivity of the laboratory tests in myasthenia gravis. Muscle Nerve(15): pp. 720-724. indentation

Ohtsuki, H., Hasebe, S., Okano, M. and Furuse, T. (1996). Strabismus surgery in ocular myasthenia gravis. Ophthalmologica 210(2): pp. 95-100.

Oosterhuis, H. (1989). The natural course of myasthenia gravis. J Neurol Neurosurg Psychiatry 52: pp. 1121-1127.

Palace, J., Newsom-Davis, J. and Lecky, B. (1998). A randomized double-blind trial of prednisolone alone or with azathioprine in myasthenia gravis. Myasthenia Gravis Study Group. Neurology 50(6): pp. 1778-1783.

Papapetropoulos, T. H., Ellul, J. and Tsibri, E. (2003). Development of generalized myasthenia gravis in patients with ocular myasthenia gravis. Arch Neurol 60(10): pp. 1491-1492.

Pascuzzi, R. M. (2003). The edrophonium test. Semin Neurol 23(1): pp. 83-88.

Phillips, L., Torner, J., Anderson, M. and Cox, G. (1992). The epidemiology of myasthenia gravis in central and western Virginia. Neurology 42: pp. 1888-1893.

Phillips, L. H. and Torner, J. C. (1996). Epidemiologic evidence for a changing natural history of myasthenia gravis. Neurology 47: pp. 1233-1238.

Roberts, P. F., Venuta, F., Rendina, E., De Giacomo, T., Coloni, G. F., Follette, D. M., Richman, D. P. and Benfield, J. R. (2001). Thymectomy in the treatment of ocular myasthenia gravis. J Thorac Cardiovasc Surg 122(3): pp. 562-568.

Roh, H. S., Lee, S. Y. and Yoon, J. S. (2011). Comparison of clinical manifestations between patients with ocular myasthenia gravis and generalized myasthenia gravis. Korean J Ophthalmol 25(1): pp. 1-7. 
Sanders, D. B. (2004). Electrophysiologic tests of neuromuscular transmission. Suppl Clin Neurophysiol 57: pp. 167-169.

Sanders, D. B. and Evoli, A. (2010). Immunosuppressive therapies in myasthenia gravis. Autoimmunity 43(5-6): pp. 428-435.

Sanders, D. B. and Stalberg, E. V. (1996). AAEM minimonograph \#25: single-fiber electromyography. Muscle Nerve 19(9): pp. 1069-1083.

Schumm, F., Wiethölter, H., Fateh-Moghadam, A. and Dichgans, J. (1985). Thymectomy in myasthenia with pure ocular symptoms. J Neurol Neurosurg Psychiatry 48: pp. 332-337.

Seybold, M. E. (1999). Diagnosis of myasthenia gravis. Myasthenia gravis and myasthenic disorders. A. G. Engel. New York, Oxford University Press: 146-166.

Sieb, J. P. and Kohler, W. (2010). Benefits from sustained-release pyridostigmine bromide in myasthenia gravis: results of a prospective multicenter open-label trial. Clin Neurol Neurosurg 112(9): pp. 781-784.

Sommer, N., Melms, A., Weller, M. and Dichgans, J. (1993). Ocular myasthenia gravis, a critical review of clinical and pathophysiological aspects. Doc Ophthalmol 84: pp. 309-333.

Sommer, N., Sigg, B., Melms, A., Weller, M., Schepelmann, K., Herzau, V. and Dichgans, J. (1997). Ocular myasthenia gravis: response to long term immunosuppressive treatment. J Neurol Neurosurg Psychiatry 62: pp. 156-162.

Somnier, F., Keiding, N. and Paulson, O. (1991). Epidemiology of myasthenia gravis in Denmark: a longitudinal and comprehensive study. Arch Neurol 48: pp. 733-739.

Srivastava, A., Kalita, J. and Misra, U. K. (2007). A comparative study of single fiber electromyography and repetitive nerve stimulation in consecutive patients with myasthenia gravis. Electromyogr Clin Neurophysiol 47(2): pp. 93-96.

Tackenberg, B., Hemmer, B., Oertel, W. H. and Sommer, N. (2001). Immunosuppressive treatment of ocular myasthenia gravis.

Tsiptsios, D., Fotiou, D. F., Haidich, A. B., Brozou, G. C., Nakou, M., Giantselidis, C., Karlovasitou, A. and Fotiou, F. (2008). Evaluation of pupil mobility in patients with myasthenia gravis. Electromyogr Clin Neurophysiol 48(5): pp. 209-218.

Ukachoke, C., Ashby, P., Basinski, A. and Sharpe, J. A. (1994). Usefulness of single fiber EMG for distinguishing neuromuscular from other causes of ocular muscle weakness. Can J Neurol Sci 21(2): pp. 125-128.

Verschuuren, J. J., Palace, J. and Gilhus, N. E. (2010). Clinical aspects of myasthenia explained. Autoimmunity 43(5-6): pp. 344-352.

Vincent, A., Bowen, J., Newsom-Davis, J. and McConville, J. (2003). Seronegative generalised myasthenia gravis: clinical features, antibodies, and their targets. Lancet Neurol 2(2): pp. 99-106.

Vincent, A., Clover, L., Buckley, C., Grimley Evans, J. and Rothwell, P. M. (2003). Evidence of underdiagnosis of myasthenia gravis in older people. J Neurol Neurosurg Psychiatry 74(8): pp. 1105-1108.

Vincent, A., Palace, J. and Hilton-Jones, D. (2001). Myasthenia gravis. Lancet 357(9274): pp. 2122-2128.

Wong, V., Hawkins, B. R. and Yu, Y. L. (1992). Myasthenia gravis in Hong Kong Chinese. Acta Neurol Scand 86: pp. 68-72.

Zhou, L., McConville, J., Chaudhry, V., Adams, R. N., Skolasky, R. L., Vincent, A. and Drachman, D. B. (2004). Clinical comparison of muscle-specific tyrosine kinase (MuSK) antibodypositive and -negative myasthenic patients. Muscle Nerve 30(1): pp. 55-60. 


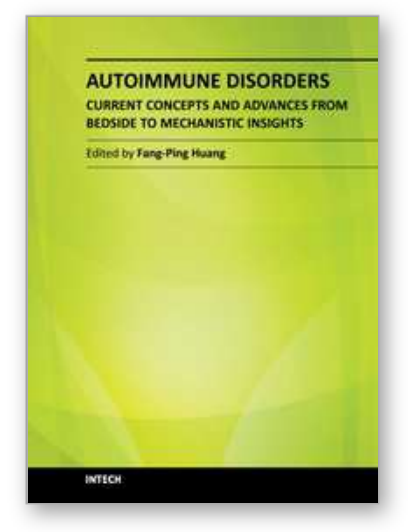

\author{
Autoimmune Disorders - Current Concepts and Advances from \\ Bedside to Mechanistic Insights \\ Edited by Dr. Fang-Ping Huang
}

ISBN 978-953-307-653-9

Hard cover, 614 pages

Publisher InTech

Published online 14, November, 2011

Published in print edition November, 2011

Autoimmune disorders are caused due to break down of the immune system, which consequently fails in its ability to differentiate "self" from "non-self" in the context of immunology. The diseases are intriguing, both clinically and immunologically, for their diversified clinical phenotypes and complex underlying immunological mechanisms. This book offers cutting-edge information on some of the specific autoimmune disease phenotypes, respective diagnostic and prognostic measures, classical and new therapeutic options currently available, pathogenesis and underlying mechanisms potentially involved, and beyond. In the form of Open Access, such information is made freely available to clinicians, basic scientists and many others who will be interested regarding current advances in the areas. Its potential readers will find many of the chapters containing in-depth analysis, interesting discussions and various thought-provoking novel ideas.

\title{
How to reference
}

In order to correctly reference this scholarly work, feel free to copy and paste the following:

Austin Hake and Henry J. Kaminski (2011). Ocular Myasthenia Analysis of Diagnostic and Treatment Options, Autoimmune Disorders - Current Concepts and Advances from Bedside to Mechanistic Insights, Dr. Fang-Ping Huang (Ed.), ISBN: 978-953-307-653-9, InTech, Available from:

http://www.intechopen.com/books/autoimmune-disorders-current-concepts-and-advances-from-bedside-tomechanistic-insights/ocular-myasthenia-analysis-of-diagnostic-and-treatment-options

\section{INTECH}

open science | open minds

\author{
InTech Europe \\ University Campus STeP Ri \\ Slavka Krautzeka 83/A \\ 51000 Rijeka, Croatia \\ Phone: +385 (51) 770447 \\ Fax: +385 (51) 686166 \\ www.intechopen.com
}

\author{
InTech China \\ Unit 405, Office Block, Hotel Equatorial Shanghai \\ No.65, Yan An Road (West), Shanghai, 200040, China \\ 中国上海市延安西路65号上海国际贵都大饭店办公楼 405 单元 \\ Phone: +86-21-62489820 \\ Fax: $+86-21-62489821$
}


(C) 2011 The Author(s). Licensee IntechOpen. This is an open access article distributed under the terms of the Creative Commons Attribution 3.0 License, which permits unrestricted use, distribution, and reproduction in any medium, provided the original work is properly cited. 